\title{
Phenological and Phytochemical Changes Correlate with Differential Interactions of Verticillium dahliae with Broccoli and Cauliflower
}

\author{
S. M. C. Njoroge, G. E. Vallad, S.-Y. Park, S. Kang, S. T. Koike, M. Bolda, P. Burman, W. Polonik, and K. V. Subbarao
}

First and ninth authors: Department of Plant Pathology, University of California, Davis, c/o United States Agricultural Research Station, CA 93905; second author: Gulf Coast Research and Education Center, University of Florida, Wimauma 33598; third and fourth authors: Department of Plant Pathology, Pennsylvania State University, University Park 16802; fifth and six authors: University of California Cooperative Extension, Salinas 93901; and seventh and eighth authors: Department of Statistics, University of California, Davis 95616. Accepted for publication 4 January 2011.

\begin{abstract}
Njoroge, S. M. C., Vallad, G. E., Park, S.-Y., Kang, S., Koike, S. T., Bolda, M., Burman, P., Polonik, W., and Subbarao, K. V. 2011. Phenological and phytochemical changes correlate with differential interactions of Verticillium dahliae with broccoli and cauliflower. Phytopathology 101:523-534.

Cauliflower (Brassica oleracea var. botrytis subvar. cauliflora) is susceptible to wilt caused by Verticillium dahliae but broccoli ( $B$. oleracea var. italica subvar. cyamosa) is not. Infection of broccoli and cauliflower by a green fluorescent protein-expressing isolate of $V$. dahliae was examined using epifluorescence and confocal laser-scanning microscopy to follow infection and colonization in relation to plant phenology. Plant glucosinolate, phenolic, and lignin contents were also assayed at 0 , 4,14 , and 28 days postinoculation. $V$. dahliae consistently infected and colonized the vascular tissues of all cauliflower plants regardless of age at inoculation, with the pathogen ultimately appearing in the developing seed; however, colonization decreased with plant age. In broccoli, $V$. dahliae infected and colonized root and stem xylem tissues of plants inoculated at 1,2 , or 3 weeks postemergence. However, $V$. dahliae colonized only the root xylem and the epidermal and cortical tissues of

broccoli plants inoculated at 4,5 , and 6 weeks postemergence. The frequency of reisolation of $V$. dahliae from the stems (4 to 22\%) and roots (10 to $40 \%$ ) of mature broccoli plants was lower than for cauliflower stems (25 to $64 \%$ ) and roots ( 31 to $71 \%$ ). The mean level of aliphatic glucosinolates in broccoli roots was 6.18 times higher than in the shoots and did not vary with age, whereas it was 3.65 times higher in cauliflower shoots than in the roots and there was a proportional increase with age. Indole glucosinolate content was identical in both cauliflower and broccoli, and both indole and aromatic glucosinolates did not vary with plant age in either crop. Qualitative differences in characterized glucosinolates were observed between broccoli and cauliflower but no differences were observed between inoculated and noninoculated plants for either broccoli or cauliflower. However, the phenolic and lignin contents were significantly higher in broccoli following inoculation than in noninoculated broccoli or inoculated cauliflower plants. The increased resistance of broccoli to $V$. dahliae infection was related to the increase in phenolic and lignin contents. Significant differential accumulation of glucosinolates associated with plant phenology may also contribute to the resistant and susceptible reactions of broccoli and cauliflower, respectively, against V. dahliae.
\end{abstract}

Verticillium wilt, caused by Verticillium dahliae Kleb., affects a broad array of horticultural and agronomic crops worldwide (23), including cauliflower (Brassica oleracea var. botrytis subvar. cauliflora) (24) and cabbage (B. oleracea var. capitata). Karapapa et al. (19) elevated Brassica spp.-infecting long-spored $V$. dahliae to $V$. longisporum. The validity of the new species designation is still being debated (23); therefore, we refer to this pathogen as $V$. dahliae in this article. $V$. dahliae infection varies by crop but is generally initiated through the root tips at the zone of cell elongation, wounded roots, and the junctions between lateral and main roots $(10,36,39,50)$. Postinfection, $V$. dahliae successfully colonizes the xylem tissues after overcoming structural barriers and prevascular defense responses (10).

Verticillium wilt of cauliflower was first reported in the United States in 1994 in California (24). Typical of many susceptible hosts of Verticillium spp., infected cauliflower plants exhibit symptoms of wilt near vegetative maturity and when plants enter the reproductive phase (24). Disease is manifested by symptoms

\section{Corresponding author: K. V. Subbarao; E-mail address: kvsubbarao@ucdavis.edu}

S. M. C. Njoroge and G. E. Vallad contributed equally to this work and should be considered joint senior authors.

doi:10.1094/PHYTO-08-10-0219

(c) 2011 The American Phytopathological Society such as the yellowing of older leaves which may turn brown, senesce, and abscise prematurely. When temperatures are higher, canopies of infected plants may wilt (44). The roots and stems of infected plants often exhibit the black or brown discolored vascular tissues characteristic of the disease. Interestingly, broccoli crops grown in coastal California fields infested with $V$. dahliae remain free of symptoms. Even though isolates of $V$. dahliae from cauliflower readily colonize roots of both broccoli and cauliflower, Verticillium wilt has only been observed on cauliflower (39). In addition, the fungus could not be recovered from mature broccoli plants $(43,44)$, possibly due to unsuccessful progression of infection into the vasculature. Therefore, broccoli could be considered a nonhost or one that expresses resistance $(31,34,46)$, even though broccoli and cauliflower are both domesticated cultivars of $B$. oleracea.

Nonhost resistance is highly effective and durable (46) but is not well understood at the molecular level. Expression profiling has identified genes that are differentially expressed in nonhost plants during pathogen challenge $(31,46)$ and may be used to further understand the differential interaction of $V$. dahliae with broccoli and cauliflower. Constitutive and induced structural and chemical barriers are often associated with nonhost resistance $(5,31,34)$. Barriers such as lignin, phenolics, and glucosinolates in broccoli may prevent $V$. dahliae from successfully colonizing vascular tissues, and may be the key to understanding the differences in host susceptibility among members of the family Brassicaceae. 
The glucosinolate-myrosinase plant defense system governs the interaction of glucosinolate-containing plants with microbes, insects, and other organisms. Glucosinolates are both constitutive and inducible secondary plant compounds found in the family Brassicaceae (Cruciferae) and 15 other plant families (5,19, 30,34). Myrosinases (EC 3.2.3.1) are enzymes that hydrolyze glucosinolates and are stored in myrosin cells, whereas glucosinolates are stored in the vacuoles of non-myrosin cells $(3,37)$. Both glucosinolates and myrosinases are found in the seed, roots, stems, and leaves (16). Upon tissue damage, such as by microbial infection, the compartmentalization of glucosinolates and myrosinase is disrupted, triggering glucosinolate hydrolysis which, in turn, results in the release of isothiocyanates, nitriles, and thiocyanates $(9,30,37)$. Because glucosinolate hydrolysis products such as isothiocyanates have antimicrobial activity against a wide range of plant pathogens $(19,27,28,38,41,42,47,54)$, including $V$. dahliae $(19,28)$, and are involved in a pathogen-induced callose response (4), glucosinolates may play a role in disease resistance $(5,19,35,37,47)$.

Only a few studies have looked at glucosinolate levels in plants after inoculating with $V$. dahliae or other pathogens. Karapapa et al. (19) inoculated B. napus with either a compatible $V$. longisporum isolate or with an incompatible $V$. dahliae isolate. They reported that glucosinolates only increased in the incompatible interaction and concluded that the increase in glucosinolates was probably responsible for the resistance response to $V$. dahliae. However, plant glucosinolate content has not always been correlated with disease resistance. Compared with the wild type, an Arabidopsis mutant with significantly decreased levels of the glucosinolate glucoraphanin (4-methylsulphinyl butyl) was not more susceptible to infection by Alternaria brassicicola, Botrytis cinerea, Erwinia carotovora, Pseudomonas syringae, or Peronospora parasitica; however, this Arabidopsis mutant was more susceptible to Fusarium oxysporum (47).

Phenolics are secondary plant metabolites that are present in the cells constitutively and also can be induced upon pathogen challenge $(29,36)$. Research into the role of plant phenolics in plant-microbe interaction showed that cell-wall-bound phenolics accumulate locally to restrict fungal penetration $(17,29,36)$. However, whether phenolics inhibit fungal growth by toxicity, strengthening the cell wall $(17,29)$, or a combination of both is not well understood.

Lignin is another phenolic compound (13) that is present in the cell wall and in the tracheids and vessel elements of the xylem, where its primary role is providing mechanical strength (45), thereby offering significant protective functions in plants. Lignification can be triggered following pathogen attack (17) or wounding (45), and the speed of its deposition and compaction may be important for successful plant defense (17). However, definitive evidence for the importance of structural and chemical strengthening of the cell wall in penetration resistance is rare (17). Pomar et al. (36) inoculated three susceptible pepper (Capsicum annuum) cultivars with $V$. dahliae and showed that stem lignin increased significantly in all three cultivars relative to noninoculated controls. More importantly, lignin content was higher in the more tolerant cultivar.

The response of broccoli and cauliflower to infection by $V$. dahliae was previously determined with an immunoenzymatic staining technique (39), revealing the similarity of cortical colonization in both hosts, but vascular colonization could not be studied with the technique. Furthermore, the role of structural or nonstructural phenolic compounds in the defense reaction of broccoli or cauliflower to infection by $V$. dahliae along with the infection of the vasculature is unknown. Therefore, the first objective of this study was to use a green fluorescent protein (ZsGreen)-expressing V. dahliae strain to determine both cortical and vascular colonization of broccoli and cauliflower after inoculation at different phenological stages. The second objective was to quantify the changes in glucosinolate, phenolic, and lignin contents in broccoli and cauliflower following inoculation with $V$. dahliae at different phenological stages to study the differential response of the two hosts. A preliminary report has been published (32).

\section{MATERIALS AND METHODS}

Plant material and fungal isolates. 'Patriot' broccoli (Sakata Seed, Morgan Hill, CA) and 'White Rock' cauliflower (Rogers/ Syngenta Seed, Boise, ID) were grown in germination flats filled with a pasteurized mixture of sand:vermiculite:peat $(4: 1: 1)$ prior to transplanting to 0.5 -liter foam cups containing the same medium. Three ZsGreen-expressing transformants (V180, V117, and V155) of the long-spored V. dahliae isolate VdBob70 from cauliflower were selected for colonization studies based on overall fluorescence and growth, morphological features, and pathogenicity to cauliflower comparable with the wild-type isolate (previous greenhouse experiments, unpublished data). Transformation of the $V$. dahliae strains was conducted using Agrobacterium tumefaciens as described by Khang et al. (20). All isolates were stored as conidial suspensions in $30 \%$ glycerol at $-80^{\circ} \mathrm{C}$. For inoculum preparation, the conidia from 14-day-old cultures grown at $25^{\circ} \mathrm{C}$ on potato dextrose agar (PDA) were collected from sterile distilled water-flooded plates, enumerated with a hemacytometer, and adjusted to $10^{6}$ spores $/ \mathrm{ml}$ with water.

Broccoli- and cauliflower- $V$. dahliae interaction experiments. The first greenhouse experiment used a three-way factorial design to evaluate (i) the inoculation of cauliflower and broccoli seedlings with either $V$. dahliae isolates V180, V117, V155, or VdBob70 or a noninoculated control; (ii) responses at either 2, 3, 4, or 5 weeks after emergence; and (iii) effect of inoculation either once, twice, or thrice over consecutive days. Treatments were arranged in a randomized complete block design and replicated three times with 18 plants per replication. Each isolate was arbitrarily assigned to separate germination trays using seedling-free rows between inoculated rows to separate inoculation treatments within a tray. Control plants were seeded in separate germination trays. At inoculation, the sand mixture surrounding the seedling in each well was drenched with either $5 \mathrm{ml}$ of a conidial suspension or with sterile distilled water for the noninoculated control. Transplanting of seedlings was staggered, based on inoculation time, with plants inoculated at 2 weeks postemergence transplanted 3 weeks later; those inoculated at 3 or 4 weeks postemergence transplanted 1 week later; and those inoculated at 5 weeks postemergence transplanted 3 days later into 0.5-liter foam-insulated cups filled with a pasteurized mixture of sand:vermiculite:peat (4:1:1).

The second greenhouse experiment was conducted with the same broccoli and cauliflower cultivars but with some treatment modifications. Only V. dahliae isolates V180 and VdBob70 were selected for the repeat study, with isolate V180 used to follow colonization and VdBob70 to measure differences in glucosinolate, lignin, and phenolic content in plants. Treatments involved inoculating broccoli and cauliflower at 1, 2, 3, 4, 5, or 6 weeks postemergence with one 5-ml aliquot of conidial suspension once each day for three consecutive days. Control plants were mock inoculated with sterile distilled water. The experiment was set up as a completely randomized design and replicated four times (10 plants per replication) for V180 and replicated three times (10 plants per replication) for VdBob70. Plants inoculated with V180 were sampled as described below (microscopy section), while VdBob70-inoculated plants were sampled at 4, 14, and 28 days postinoculation.

In addition, 6 weeks after transplanting, four plants were arbitrarily selected from each treatment inoculated with V180 and the noninoculated control to reisolate $V$. dahliae. The roots and stems of each cauliflower and broccoli plant were washed with 
tap water and cut into $1-\mathrm{cm}$ sections, disinfested in $0.5 \% \mathrm{NaOCl}$ for $2 \mathrm{~min}$, rinsed in sterile distilled water for $3 \mathrm{~min}$, blotted dry, and placed on a modified Sorenson's NP10 medium (18). The NP10 dishes were then incubated at room temperature in the dark and examined 1 to 2 weeks later for fluorescent and nonfluorescent colonies of $V$. dahliae.

Microscopy. Broccoli and cauliflower plants were sampled at 48 and $96 \mathrm{~h}$ after inoculation in both experiments, and again at 1 and 2 weeks after inoculation, 1 and 2 months after inoculation, flowering, seed-set, and senescence. At each sampling, whole plants were gently pulled up and the roots washed with tap water. Samples were mounted either whole or hand sectioned and examined with an epifluorescence Olympus BX60 compound microscope, an epifluorescence Olympus SZX12 stereo microscope, or an epifluorescence Nikon compound microscope coupled to a MRC1024 Bio-Rad Confocal System (Bio-Rad, Hercules, CA). Images were captured and processed as outlined by Vallad and Subbarao (50).

Reisolation of $\boldsymbol{V}$. dahliae from seed. In all, $\approx 25$ seeds from each treatment were collected from both experiments, disinfested as described above, and plated on NP10 medium. Petri dishes were incubated in the dark and examined 1 week later for seed germination and the presence of fluorescent and nonfluorescent colonies of $V$. dahliae.

Glucosinolate assay. To ensure that adequate plant material was available for analysis, sample sizes varied depending on the phenological stage of the plants. For seedlings sampled during 1 to 3 weeks postemergence, one sample consisted of 10 plants whereas, for seedlings sampled at 4 weeks postemergence and beyond, a sample consisted of 5 plants. Sampled plants were immediately frozen in liquid nitrogen. The roots and shoots were then separated, cut into small pieces, and freeze dried. Glucosinolates were extracted as outlined by Magrath et al. (26) with the modifications of Kirkegaard and Sarwar (22). To identify and quantify desulfoglucosinolates, eluted samples were analyzed at Clemson University's Multi-user Laboratory using a Hewlett Packard 1090 high-pressure liquid chromatograph (Agilent Technologies, Wilmington, DE) equipped with a diode array detector and operating conditions described by Njoroge et al. (33). Benzyl glucosinolate and sinigrin were used as internal standards. To identify sample peaks, retention times were compared with pure glucosinolate standards: desulfoglucotropaeolin (benzyl), desulfosinigrin (prop-2-enyl), desulfoglucoerucin (4-[methylthio]-butyl), desulfoglucobarbarin (2-hydroxy-2-phenythyl), desulfoglucocheirolin (3-methylsulfonyl propyl), desulfoglucoraphanin (4methylsulfinyl butyl), desulfoglucosibarin (2-hyroxy-2-phenethyl), and desulfoglucoraphanin (4-[methyl sulfinyl] but-3-enyl). Concentrations of glucosinolates extracted from broccoli and cauliflower were determined using response factors for desulphoglucosinolates published by the European Economic Community (7).

Phenolic assay. The sampling scheme was the same as that described for the glucosinolate assay. Plant samples were washed free of soil and then cut at the crown, roots, and shoots, frozen in liquid nitrogen, and stored at $-20^{\circ} \mathrm{C}$ until analyzed. Frozen samples were homogenized with a pestle and mortar; a subsample was weighed and then dried at $50^{\circ} \mathrm{C}$ to determine the dry weight. Phenolics were extracted using procedures outlined by Torti et al. (48), with modifications. For each sample, ground tissue (wet weight equivalent to $100 \mathrm{mg}$ of dry weight) was distributed evenly into four 2-ml centrifuge tubes to which $1.5 \mathrm{ml}$ of $85 \%$ methanol ( $\mathrm{vol} / \mathrm{vol})$ was added, and the tubes were capped. The tubes were then placed in a Retsch TissueLyser (Retsch Inc., Newtown, PA) which was run for $60 \mathrm{~s}$ at maximum speed. After centrifuging the tubes at $1,600 \times g$ for $15 \mathrm{~min}$, the supernatant was saved and the pellet was resuspended in $1.5 \mathrm{ml}$ of $85 \%$ methanol, and the extraction procedure was repeated once. The supernatants from each sample were combined and total phenolic content was measured by spectrophotometric analysis, using the
Folin-Ciocalteu method outlined by Singleton and Rossi (40) that was later modified by Kim et al. (21). Briefly, a 0.4-ml aliquot of the extract was mixed with $5.2 \mathrm{ml}$ of deionized distilled water. A reagent blank was prepared with $5.6 \mathrm{ml}$ of deionized distilled water. A $0.4-\mathrm{ml}$ aliquot of Folin-Ciocalteu reagent was added to each and the solutions were hand shaken for mixing. After adding $4 \mathrm{ml}$ of $2 \mathrm{M} \mathrm{Na}_{2} \mathrm{CO}_{3}$ solution, the tubes were held at 24 to $25^{\circ} \mathrm{C}$ for $90 \mathrm{~min}$. The absorbance at $750 \mathrm{~nm}$ was obtained using a Biomate 3 UV-Visible spectrophotometer (Thermo Fisher Scientific Inc., Waltham, MA). Tannic acid (Sigma-Aldrich, St. Louis) was used for the standard calibration curve (48). Sample phenolics were quantified as milligrams of tannic acid equivalent per gram of dry weight, and the samples were run in triplicate.

Lignin assay. After phenolic extraction, the alcohol-insoluble residue was air dried for $24 \mathrm{~h}$. After drying, $50 \mathrm{mg}$ of the insoluble pellet was then put in Teflon-lined glass vials (16 by $150 \mathrm{~mm}), 10 \mathrm{mM}$ potassium buffer $\left(\mathrm{pH} 6 ; 0.02 \% \quad \mathrm{NaN}_{3}\right)$ (Teknova, Hollister, CA) at $30 \mathrm{ml} / \mathrm{g}$ was added, and the vials were capped. The pellet was heated and destarched as described by Hartfield and Weimer (14). After destarching, 20 to $25 \mathrm{mg}$ of the cell wall samples were placed into culture tubes which were then held in a vacuum desiccator over polyphosphoric acid for at least $18 \mathrm{~h}$ before analysis, then treated with acetyl bromide reagent (Alfa Aesar, Ward Hill, MA) as described by Hartfield and Weimer (14). The samples were then heated in dry blocks for $4 \mathrm{~h}$ at $50^{\circ} \mathrm{C}$ and transferred into flasks containing a solution of $10 \mathrm{ml}$ of $2 \mathrm{M} \mathrm{NaOH}$ and $12 \mathrm{ml}$ of glacial acetic acid (Strem Chemicals, Newburyport, MA). A $1.75-\mathrm{ml}$ aliquot of $0.5 \mathrm{M}$ hydroxylamine was added to each flask and absorption obtained at $280 \mathrm{~nm}$ (14) using a Biomate 3 UV-Visible spectrophotometer. Samples were run in triplicate.

Statistical analysis. Identified glucosinolates were classified into aliphatic (glucoiberin, glucoraphanin, glucoerucin, gluconapin, progoitrin, and others), aromatic (nasturtiin), and indole (glucobrassicin, hydroxyglucobrassicin, methoxyglucobrassicin, neoglucobrassicin, and others) types for statistical analysis, and the data were treated separately. The effects of inoculation (versus control), plant age at inoculation (age), time from inoculation (time), plant (broccoli or cauliflower), tissues sampled (root versus shoot), and interactions were analyzed. Of the four types of analyses employed, the first focused on the mean quantity of each glucosinolate type (aliphatic, aromatic, and indole), and the other three analyses focused on the frequency of each glucosinolate type (aliphatic, aromatic, and indole). Stepwise regression in the general linear models was employed for the mean quantity of each glucosinolate type, and the count data available for the three types of glucosinolates were analyzed using either logistic or Poisson regression. Because the number of aliphatic and indole glucosinolates observed was random, Poisson instead of binomial regression was more appropriate for these data. Because only one type of aromatic glucosinolate was observed, the presence or absence of this glucosinolate was better analyzed by logistic than binomial regression. All analyses were conducted in a stepwise manner, with the corresponding cut-off values for inclusion or exclusion of independent variables ( $t$-to enter and $t$-to delete, respectively) set at 2.0. The stepwise regression method constitutes an empirical model building or selection methodology. In other words, the models do not constitute scientific models that were built a priori. Nevertheless, the hypothesis used in the model building are based in empirical evidence. For instance the inclusion of the variable Time14 was based on the evidence that the glucosinolate levels tend to undergo significant changes 2 weeks after inoculation.

Phenolic and lignin data were analyzed as repeated measures using PROC GLM of SAS (release 9.1; SAS Institute, Cary, NC). Interaction effects of plant age at inoculation-change in phenolic or lignin content over time were significant $(P<0.001)$ for cauliflower and broccoli. Therefore, single degree-of-freedom contrast 
statements were used to compare phenolic or lignin concentrations at each sampling period within and across broccoli and cauliflower samples.

\section{RESULTS}

Colonization of cauliflower up to 1 month postinoculation. Conidia germinated and infected cauliflower seedlings 72 to $96 \mathrm{~h}$ postinoculation, mostly at the lateral root tips or within the root elongation zone (Fig. 1A and B), and also through wounds (data not shown). No appressoria were observed (data not shown). The observed level of root colonization decreased with increased time between emergence and inoculation. Cauliflower seedlings inoculated at 1 week after emergence became chlorotic, and $16 \%$ of these seedlings wilted within 2 weeks of inoculation. Xylem vessels within lateral and main roots of wilted plants were heavily colonized and some roots collapsed completely (data not shown). Unlike broccoli, lateral root surfaces of cauliflower plants inocu-

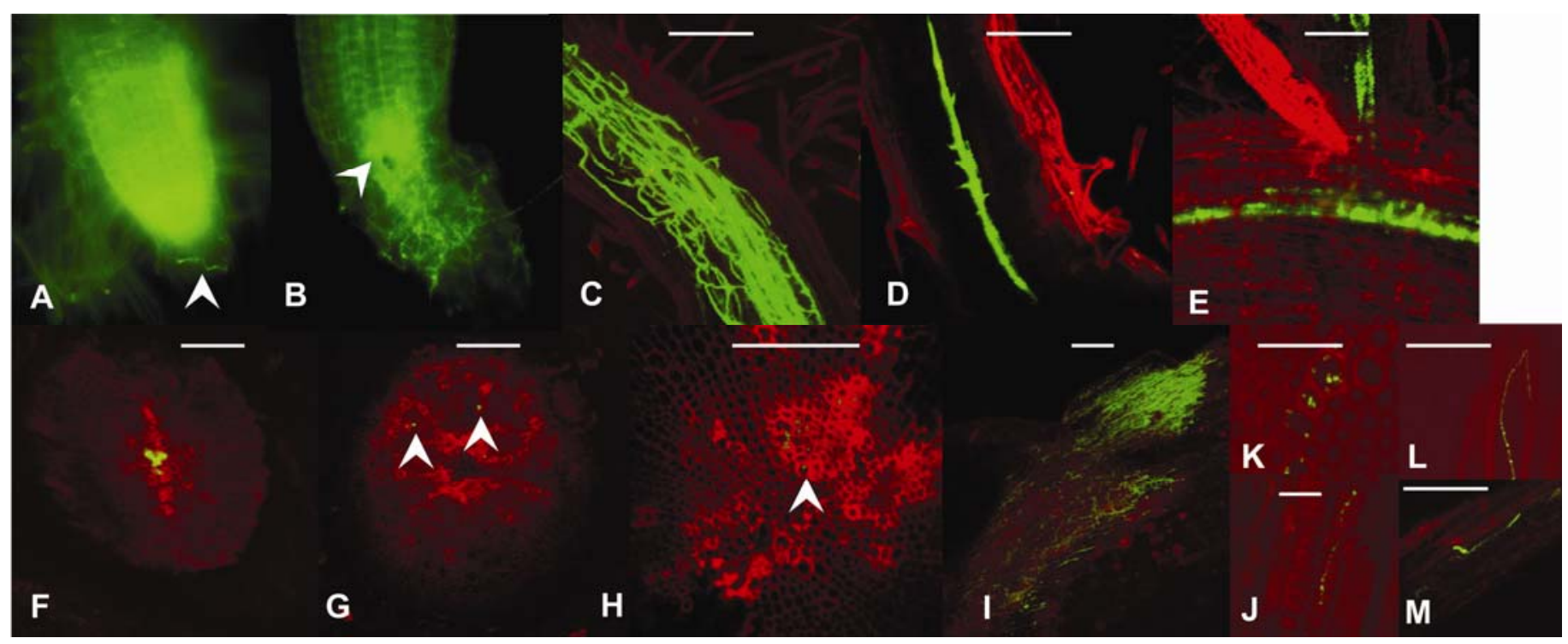

Fig. 1. Infection and colonization events on cauliflower ('White Rock') by Verticillium dahliae expressing green fluorescent protein isolate up to 1 month postinoculation. A and B, At 72 to $96 \mathrm{~h}$ postinoculation, conidia geminated and infected plants mainly at the root tip. C, Compared with broccoli, cauliflower lateral roots were colonized more intensely. D, Only the lateral and main root xylem of seedlings inoculated at 1 and 2 weeks postemergence were heavily colonized, and infection was observed moving systemically into $\mathbf{E}$, main and $\mathbf{F}$, hypocotyl xylem (hypocotyl cross section). G and $\mathbf{H}$, For plants inoculated at 3 to 5 weeks postemergence, the main root xylem was less intensely colonized (root cross sections) and the fungus was not observed in the stem xylem of these plants. $\mathbf{I}, V$. dahliae colonized the main root surface of plants inoculated 6 weeks postemergence but the fungus was not found in the main root xylem of these plants. $\mathbf{J}$ to $\mathbf{M}, V$. dahliae hyphae in the xylem. Conidia were not observed. Images captured using $\mathbf{A}$ and $\mathbf{B}$, epifluorescence microscopy and $\mathbf{C}$ to $\mathbf{M}$, confocal laser scanning microscopy. J to M, Scale bars $=50 \mu \mathrm{m}$. C, D, and H, Scale bars $=100 \mu \mathrm{m}$. E, F, and G, Scale bars $=200 \mu \mathrm{m}$. I, Scale bar $=400 \mu \mathrm{m}$.

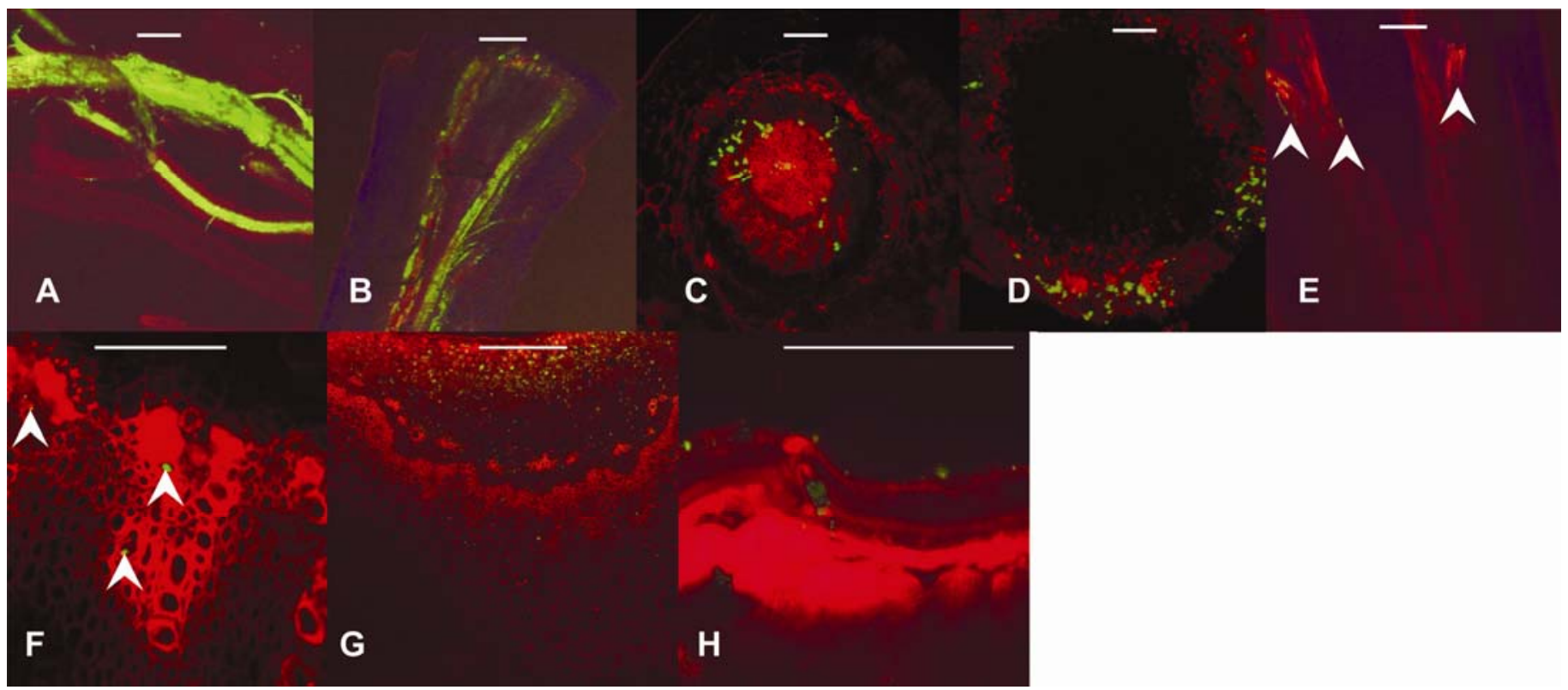

Fig. 2. Verticillium dahliae-cauliflower interaction from 1 month postinoculation to seed-set. A, Root colonization was more intense on plants inoculated 1 to 2 weeks postemergence. B, $V$. dahliae colonization of the stem xylem (longitudinal section); both C, lower (cross section) and $\mathbf{D}$, upper (cross section) stem was more intense for plants inoculated at 1 to 2 weeks compared with $\mathbf{E}$, those inoculated at 3 to 6 weeks postemergence (longitudinal section of the stem). F, Unlike in broccoli, $V$. dahliae was always found in the stem xylem for plants inoculated at 3 to 6 weeks (cross section). G, Fungus was observed in the xylem and cortical tissues at the base of the floral stalk (cross section of the floral stalk) and $\mathbf{H}$, frequently in a cross sections of the seed coat. All images were captured using confocal laser scanning microscopy. C, D, F, G, and H, Scale bars $=100 \mu \mathrm{m}$. A, B, and E, Scale bars $=400 \mu \mathrm{m}$. 




Fig. 3. Infection and colonization events on broccoli ('Patriot') by Verticillium dahliae expressing green fluorescent protein isolate up to 1 month postinoculation. A, At 72 to $96 \mathrm{~h}$ postinoculation, infection and colonization mainly occurred at the root tip. B, V. dahliae also colonized lateral and main root surfaces, although colonization was less intense compared with that on cauliflower roots. C, V. dahliae infected main roots and was observed in the hypocotyl xylem of plants inoculated at 1 and 2 weeks postemergence (cross section). D, For plants inoculated at 3 weeks postemergence, the fungus was observed in the main root or crown xylem (cross section). However, colonization of these vessels was low. V. dahliae was only observed in the epicotyl xylem vessels of plants inoculated 1 to 2 weeks postemergence. For plants inoculated at 4 to 6 weeks postemergence, $\mathbf{E}, V$. dahliae-broccoli interaction was mainly limited to the root surfaces and $\mathbf{F}$, infections were mostly limited to the epidermal or cortical root tissue (root cross section); and $\mathbf{G}$, most lateral roots next to the main root were free from infection (cross section). H, However, in one plant sample inoculated at 5 weeks postemergence, $V$. dahliae was observed in the main root xylem vessels (cross section) but not in the stem xylem. Images were captured using A, epifluorescence microscopy and $\mathbf{B}$ to $\mathbf{H}$, confocal laser scanning microscopy. $\mathbf{B}$ to $\mathbf{D}$, $\mathbf{F}$, and $\mathbf{H}$, Scale bars $=100 \mu \mathrm{m}$. E and $\mathbf{G}$, Scale bars $=400 \mu \mathrm{m}$.

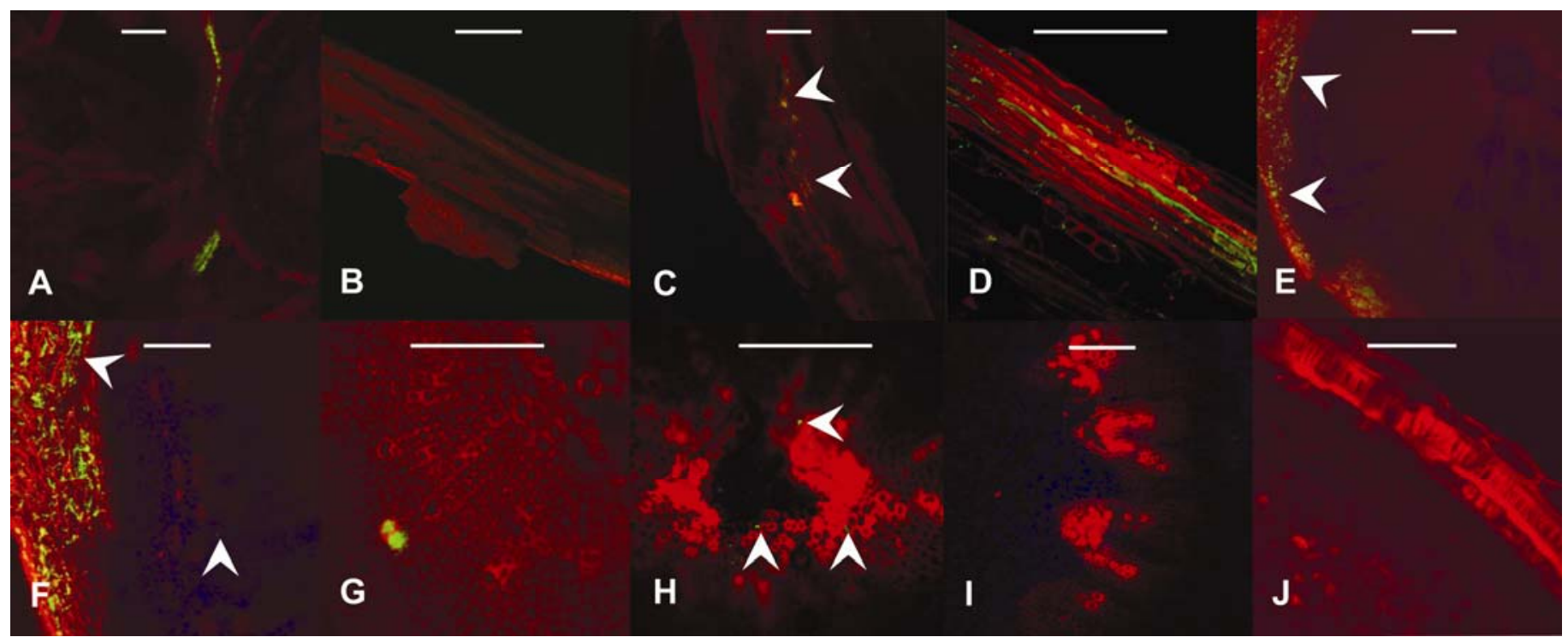

Fig. 4. Verticillium dahliae-broccoli interaction from 1 month postinoculation to seed-set. A, V. dahliae was invariably grew on the root surface of plants inoculated at 1 to 6 weeks postemergence. Lesions were observed $\mathbf{B}$, on lateral roots and $\mathbf{C}$, in some parts the cortex, had sloughed off, exposing the xylem, where the green fluorescent protein signal from the fungus was apparent. D, When sections were cut from these lesions and mounted, intense colonization by $V$. dahliae was observed in the xylem vessels (longitudinal section of the root lesion). For plants inoculated at 4 to 6 weeks postemergence, limited main root xylem colonization was observed. Mostly root surface and cortical infections were observed; $\mathbf{E}$ and $\mathbf{F}$, shown here are cross sections of the crown. $\mathbf{G}$ and $\mathbf{H}$, However, for plants inoculated at 1,2, and 3 weeks postemergence, V. dahliae was occasionally observed in the lower and upper stem xylem (stem cross sections) but $\mathbf{I}$, not in plants inoculated at 4 to 6 weeks postemergence (epicotyl cross section). J, Fungus was not observed in the floral tissues or in broccoli seed. All Images were captured using confocal laser scanning microscopy. D, G, H, and J, Scale bars $=100 \mu \mathrm{m}$. B, F, and I, Scale bars $=200 \mu \mathrm{m}$. A, C, and E, Scale bars $=400 \mu \mathrm{m}$. 
lated at 1 to 6 weeks postemergence were heavily colonized (Fig. $1 \mathrm{C}$ and D). The xylem vessels of lateral and main roots of cauliflower seedlings inoculated at 1 and 2 weeks postemergence were heavily colonized with systemic infections that progressed pathogen was not observed in the main root xylem of plants inoculated at 6 weeks postemergence but $V$. dahliae colonized the epidermal tissues of the main root (Fig. 1I). Hyphae of $V$. dahliae were also observed in xylem vessels, and appeared to grow from one adjacent vessel to the next (Fig. 1J to M).

Colonization of cauliflower 1 month postinoculation to seed-set. After 1 month, colonization by $V$. dahliae was more extensive along the roots of cauliflower seedlings inoculated at 1 and 2 weeks postemergence (Fig. 2A) than seedlings inoculated 3 to 6 weeks postemergence (not shown); a similar difference in the colonization of xylem vessels within stems was also apparent (Fig. 2B, C, and D, representing plants inoculated at 1 to 2 weeks postemergence; compared with $\mathrm{E}$ and $\mathrm{F}$, representing plants inoculated at 3 to 6 weeks postemergence). Regardless of seedling age at the time of inoculation, $V$. dahliae readily colonized vascular tissues in the stem of cauliflower plants, including the inflorescence (Fig. 2G), and seed (Fig. 2H).

Colonization of broccoli up to 1 month postinoculation. Conidia of $V$. dahliae germinated and directly infected lateral roots of broccoli 72 to $96 \mathrm{~h}$ postinoculation; no appressoria were observed (data not shown). Penetration and infection occurred mostly behind the root tip at the zone of root elongation (Fig. $3 \mathrm{~A})$. The pathogen also germinated and colonized root surfaces proximal to the root tips (Fig. 3B), including the junction of main and lateral roots and other wounds along the root surface (data not shown). Infection and colonization of root vascular tissues decreased with increased age of broccoli seedlings at inoculation. For broccoli seedlings inoculated at 1,2, and 3 weeks postemergence, $V$. dahliae successfully infected the xylem in the main root but was only observed in the xylem within the hypocotyl of seedlings inoculated at 1 and 2 weeks postemergence (Fig. 3C) and in the xylem at the crown of seedlings inoculated at 3 weeks postemergence (Fig. 3D). Only occasionally was $V$. dahliae observed in epicotyl xylem vessels of broccoli plants inoculated at 1 and 2 weeks postemergence; however, colonization was limited to a few vessels (data not shown). In contrast, for broccoli seedlings inoculated at 4 to 6 weeks postemergence, colonization was observed along main and lateral root surfaces (Fig. 3E), mostly limited to epidermal or cortical tissues (Fig. 3F). Most lateral roots next to the main root were free from infection (Fig. $3 \mathrm{G})$. V. dahliae was observed only once in xylem vessels of the main root in one broccoli plant inoculated at 5 weeks postemergence (Fig. $3 \mathrm{H}$ ) but not in the stem of this or any other plants

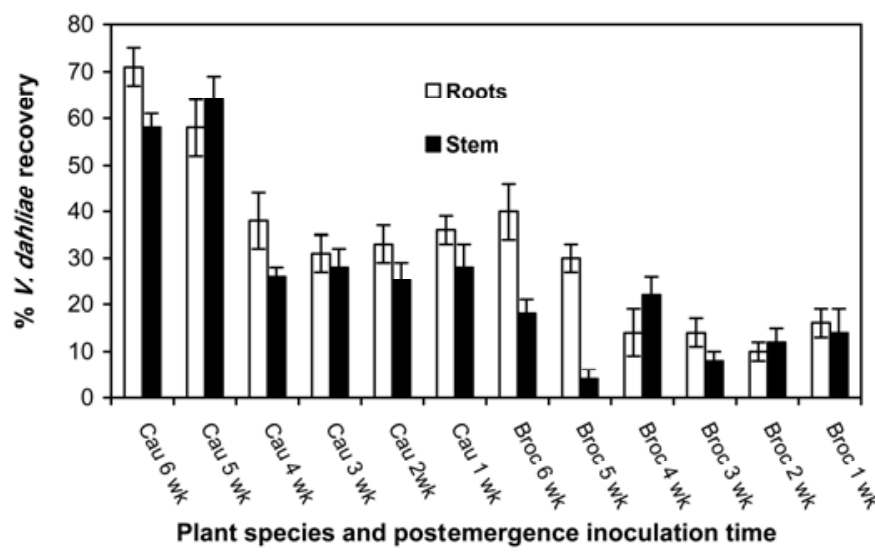

Fig. 5. Recovery of Verticillium dahliae from broccoli (Broc) and cauliflower (Cau) plants, inoculated at 1, 2, 3, 4, 5, or 6 weeks postemergence. Roots and shoots were sampled from plants at head formation. Error bars represent one standard error of the mean. from the lateral to main root (Fig. 1E) and into the stem (Fig. 1F). The xylem of main roots from cauliflower seedlings inoculated at 3 to 5 weeks postemergence exhibited less colonization (Fig. 1H), with no detectable vascular colonization of stem tissues. The inoculated 4 to 6 weeks postemergence. Over the course of these studies, infected broccoli plants never exhibited any symptoms of wilt.

Colonization of broccoli 1 month postinoculation to seedset. $V$. dahliae had colonized the surfaces of lateral and main roots of inoculated broccoli plants after 4 weeks (Fig. 4A). Interestingly, lesions appeared on lateral roots where V. dahliae colonized the xylem (Fig. 4B and C). For broccoli plants inoculated at 4 to 6 weeks postemergence, epidermal and cortical infections of the main roots were frequently observed (Fig. 4D to H). Regardless of inoculation time, $V$. dahliae was never observed or recovered from the floral tissues or seed of broccoli.

Reisolation of $\boldsymbol{V}$. dahliae from inoculated plants. $V$. dahliae was recovered from roots and stems of mature broccoli and cauliflower plants (Fig. 5). In cauliflower, the fungus was recovered at a higher frequency from plants inoculated at 5 and 6 weeks postemergence than those inoculated at 1 to 4 weeks postemergence. The frequency of recovery from roots and stems of inoculated broccoli plants was less compared with cauliflower. Similar to cauliflower, recovery from broccoli roots was greatest in plants inoculated at 5 and 6 weeks postemergence. However, the recovery of $V$. dahliae from the stems of broccoli was less frequent than was for cauliflower, especially for plants inoculated at 5 to 6 weeks postemergence (Fig. 5).

Of the seed collected from inoculated cauliflower and broccoli plants, 95 and $97 \%$ germinated, respectively. No V. dahliae was recovered from broccoli or cauliflower seed tested on NP10 medium (data not shown).

Glucosinolates in broccoli and cauliflower. The different glucosinolates identified in broccoli and cauliflower are listed in Table 1. Among the aliphatic glucosinolates, glucoraphanin was present in both roots and shoots of broccoli but was absent in cauliflower. Although the glucoraphanin levels incrementally increased with plant age in the shoots of broccoli, levels did not change in the roots. Similarly, levels of the aliphatic glucosinolate glucoiberin remained relatively stable in both the shoots and roots of cauliflower but were not detected in broccoli (Table 1). Another aliphatic glucosinolate, progoitrin, was present at nearly all growth stages in the shoots of cauliflower but was rarely present in the roots of cauliflower or in the roots and shoots of broccoli (Table 1). Among the indole glucosinolates, neoglucobrassicin was detected only in the shoots of cauliflower (Table 1). For the lone aromatic glucosinolate, nasturtiin, no clear temporal distribution was detected within either broccoli or cauliflower. However, nasturtiin was detected in the roots of both broccoli and cauliflower at and after 3 and 4 weeks postemergence, respectively (Table 1).

The stepwise regression methods with mean glucosinolate levels revealed significant differences between broccoli and cauliflower, age of plants at inoculation, and time from inoculation (Table 2). In addition, interactions of plant-tissues sampled as well as age at inoculation-tissues sampled were also significant (Table 2). For broccoli, the mean glucosinolate levels between root and shoot did not vary regardless of plant age at inoculation. However, for cauliflower, the mean glucosinolate levels in shoots were $\approx 2.95$ higher than in the roots. The mean glucosinolate levels in cauliflower roots were 1.53 times higher than in broccoli roots regardless of plant age. In contrast, mean glucosinolate levels were $\approx 1.42$ times lower in cauliflower shoots than in broccoli roots at all phenological stages.

In the stepwise Poisson regression for the aliphatic glucosinolates as the response variable, plant tissue, the interaction of plant (=crop)-age and plant-plant tissue (shoot or root), and glucosinolate mean were selected as the significant variables 
(Table 3). The mean level of aliphatic glucosinolates detected in broccoli roots was $e^{(1.82)}=6.18$ times higher than the number detected in shoots. The level of aliphatic glucosinolates detected in both roots and shoots of broccoli was consistent regardless of plant age. In contrast, at any given age in cauliflower, the mean level of aliphatic glucosinolates detected in the shoots of cauliflower was $e^{(1.29)}=3.65$ times higher than in the roots, and the types of glucosinolates varied with age. The mean number of aliphatic glucosinolates detected in the roots of cauliflower increased by $48 \%$ per week. This functional relationship is denoted by $($ mean $[$ Age +7$]-$ mean $[$ Age $]) /$ mean $($ Age $)$ of $e^{(7 \times 0.0556)-1}=0.48$.

Because only a few data points were available for the aromatic glucosinolates, we decided to relate the chance of finding this type of glucosinolate on the explanatory variable-inoculation versus control, plant age at inoculation (age), time from inoculation (time), plant (broccoli or cauliflower), and tissue sampled (root versus shoot) - using a stepwise logistic regression method (i.e., considering only the presence or absence of the aromatic glucosinolates). The significant variables selected were plant, plant tissue sampled (Tissue), Time (from inoculation), Plant $\times$ Age (phenological stage at inoculation), and Tissue $\times$ Time14, where Time $14=$ Time -13 for Time $>13$ and Time $14=0$ for Time $\leq 13$ (Table 4). The hypothesis tested suggests that the nature of relationship between the response variables in our models and Age is different before and after 2 weeks after inoculation. This is modeled by the inclusion of the variable Time14.

The probability of finding the aromatic glucosinolate in the roots of broccoli varied with time, and this dependence is given by the relationship $e^{(0.6676+0.1156 \times \text { Time })}$. This probability for cauliflower varied with Age and Time as $e^{(0.6676-10.7361+0.1156 \times \text { Time }+1.7926 \times \text { Age })}$. Thus, the corresponding odds ratio (cauliflower/broccoli) depended only on Age and the relation is given by $e^{(-10.7361+1.7926 \times \text { Age })}$. In the shoots, however, the probability for the presence of aromatic glucosinolates for broccoli varied with Time as $e^{(0.6676-2.2491+0.1156 \times \text { Time })}$ for Time $<13(<2$ weeks after inoculation) and $e^{(0.6676-2.2491+0.1156 \times \text { Time }-0.1594 \times[\text { Time }-13])}$ for Time $>13$ (>2 weeks after inoculation). This probability for cauliflower also depended on Age, and the relation is given by $e^{(0.6676-10.7361-2.2491+0.1156 \times \text { Time }+1.7926 \times \text { Age })}$ for Time $<13$ and by $e^{(0.6676-10.7361-2.2491+0.1156 \times \text { Time }+1.7926 \times \text { Age }-0.1594 \times[\text { Time }-13])}$ for Time $>13$. Thus, the odds ratio (cauliflower/broccoli) for the presence of aromatic glucosinolates in the shoots was the same as for the roots given above and plotted in Figure 6A.

For broccoli, the odds ratio for the presence of aromatic glucosinolates in shoots versus roots varied with Time14 and the

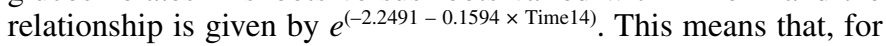

TABLE 1. Final concentrations of glucosinolates ( $\mu \mathrm{mol} / \mathrm{g}$ of dry tissue measured 1 month after inoculation) identified at various phenological stages in the roots and shoots of broccoli and cauliflower following inoculation with a crucifer strain of Verticillium dahliae (VdBob70)

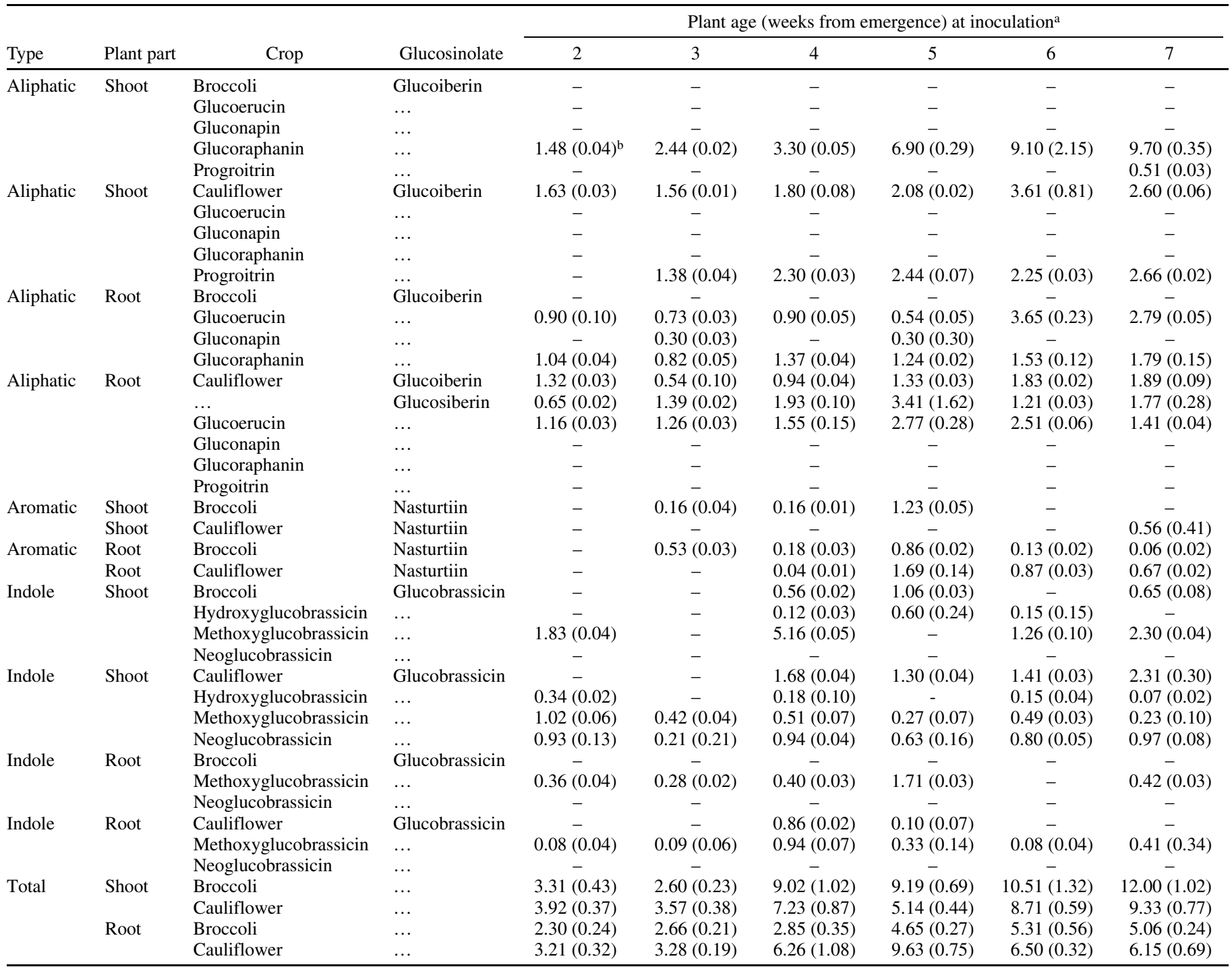

a Symbol: - indicates glucosinolates not present at sampling time.

${ }^{b}$ One standard error of the mean. 
Time $<13$, this odds ratio equals $e^{(-2.2491)}$ and, for Time $>13$, it is $e^{(-2.2491-0.1594 \times(\text { Time }-13))}$. For cauliflower, the odds ratio for the presence of aromatic glucosinolates in shoots versus roots varied with Age similar to broccoli (Fig. 6B).

The mean number of indole glucosinolates detected did not vary with age (Table 5). The mean number of indole glucosinolates detected in cauliflower shoots was $e^{(0.9583)}=2.61$ times higher than that detected in any of the other three combinations of plant and plant tissue sampled (cauliflower-roots, broccolishoots, and broccoli-roots).

Phenolics in broccoli and cauliflower. In general, phenolics accumulated more in broccoli plants inoculated at 3 to 6 weeks postemergence compared with those inoculated at 1 or 2 weeks postemergence (Fig. 7A). At 4 to 28 days after inoculation, phenolic concentration was significantly higher in broccoli plants inoculated at 3 to 6 weeks postemergence compared with the noninoculated control $(P \leq 0.002)$ but not with broccoli inoculated at 1 and 2 weeks postemergence $(P>0.05)$. At 4 days postinoculation, the phenolic concentration was significantly higher in broccoli inoculated at 2 to 6 weeks postemergence, compared with the phenolic concentrations in these plants at 14 or 28 days postinoculation (Fig. 7A).

TABLE 2. Variables significant in the stepwise regression analysis of the mean glucosinolate levels in broccoli and cauliflower

\begin{tabular}{lccrc}
\hline Variable $^{\mathrm{a}}$ & Coefficient & $\begin{array}{c}\text { Standard } \\
\text { error }\end{array}$ & $t$ statistic & $P$ value \\
\hline Intercept & -1.6494 & 0.3315 & -4.9751 & 0.0000 \\
Veg & 1.5251 & 0.2879 & 5.2978 & 0.0000 \\
Age & 0.7320 & 0.0678 & 10.7893 & 0.0000 \\
Time & 0.0892 & 0.0090 & 9.8555 & 0.0000 \\
Veg $\times$ tissue & -2.9500 & 0.3949 & -7.4710 & 0.0000 \\
Age $\times$ tissue & 0.8119 & 0.0580 & 13.9957 & 0.0000 \\
\hline
\end{tabular}

${ }^{\mathrm{a}}$ Veg $=$ broccoli or cauliflower, age $=$ phenological stage at inoculation, tissue $=$ root or shoot, and time $=$ time from inoculation. The coefficient of determination for this regression was 0.7756 with an adjusted value of 0.7708 .

TABLE 3. Variables selected as significant in the stepwise Poisson regression analysis of the number of aliphatic glucosinolates in broccoli and cauliflower

\begin{tabular}{lcccc}
\hline Variable $^{\mathrm{a}}$ & Coefficient & $\begin{array}{c}\text { Standard } \\
\text { error }\end{array}$ & $t$ statistic & $P$ value \\
\hline Intercept & 1.6272 & 0.0613 & 26.5231 & 0.0000 \\
Tissue & -1.8218 & 0.1203 & -6.8304 & 0.0000 \\
Veg $\times$ age & 0.0556 & 0.0158 & 3.5186 & 0.0000 \\
Veg $\times$ tissue & 0.5277 & 0.1353 & 3.8985 & 0.0000 \\
Gluc mean & 0.0461 & 0.0139 & 3.3218 & 0.0000 \\
\hline
\end{tabular}

${ }^{\text {a }}$ Veg $=$ broccoli or cauliflower, age $=$ phenological stage at inoculation, tissue $=$ root or shoot, and gluc mean $=$ mean amount of aliphatic glucosinolates .

TABLE 4. Variables selected as significant in the stepwise logistic regression analysis of the presence or absence of the nasturtiin (the only aromatic glucosinolate detected) in broccoli and cauliflower

\begin{tabular}{lcccc}
\hline & \multicolumn{3}{c}{ Standard } \\
Variable $^{\mathrm{a}}$ & Coefficient & error & $t$ statistic & $P$ value \\
\hline Intercept & 0.6676 & 0.4030 & 1.6565 & 0.0000 \\
Veg & -10.7361 & 1.9775 & -5.4291 & 0.0000 \\
Tissue & -2.2491 & 0.4806 & -4.6800 & 0.0000 \\
Time & 0.1156 & 0.0324 & 3.5682 & 0.0000 \\
Veg $\times$ age & 1.7926 & 0.3391 & 5.2869 & 0.0000 \\
Tissue $\times$ time14 & -0.1594 & 0.0591 & -2.6955 & 0.0080 \\
\hline
\end{tabular}

a Veg $=$ broccoli or cauliflower, age $=$ phenological stage at inoculation, tissue $=$ root or shoot, and time14 = two weeks after inoculation. The response variable (presence or absence of nasturtiin) was defined as present $(=1)$ if nasturtiin was present in at least one of the three replicates, and absent $(=0)$ otherwise.
A significant accumulation of phenolics occurred 4 days postinoculation in cauliflower inoculated at 2 to 6 weeks postemergence. Compared with the noninoculated control, all inoculated cauliflower plants had significantly higher phenolic content at 14 days postinoculation (Fig. 7B). Interestingly, phenolic accumulation in cauliflower was not related to the age at which the plants were inoculated (Fig. 7B).

Lignin levels in broccoli and cauliflower. From 4 to 28 days postinoculation, lignin content was significantly higher $(P \leq 0.05)$ in inoculated broccoli plants compared with the noninoculated control (Fig. 8A). The highest concentration of lignin was recorded at 14 days postinoculation in broccoli inoculated at 4,5 , and 6 weeks postemergence relative to the nontreated control and also to plants inoculated at 1, 2 or 3 weeks postemergence (Fig. 8A). However, lignin content measured among inoculated broccoli plants at 28 days postinoculation was not significant (Fig. 8A).

At 4 to 28 days after inoculation, lignin concentration in cauliflower plants inoculated at 5 or 6 weeks postemergence was
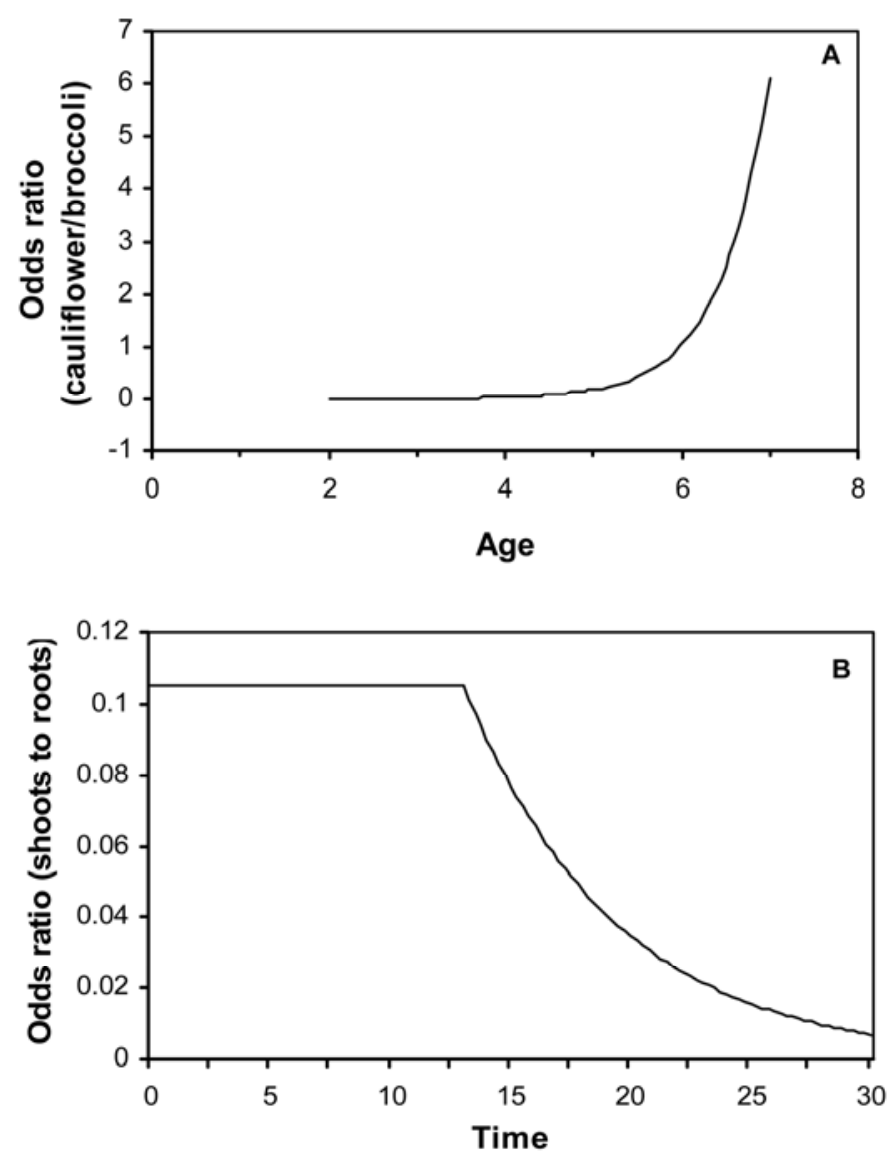

Fig. 6. Odds ratio (cauliflower/broccoli) for the presence of aromatic glucosinolates in the shoots and roots varies with age at inoculation and is given by the functional relationship $e^{(-10.7361+1.7926 \times \text { Age })}$ and with time from inoculation given by the relationship $e^{(-2.2491-0.1594 \times \text { Time14) }}$.

TABLE 5. Variables selected as significant in the stepwise Poisson regression analysis of the number of indole glucosinolates present in broccoli and cauliflower

\begin{tabular}{lccrc}
\hline Variable $^{\mathrm{a}}$ & Coefficient & $\begin{array}{c}\text { Standard } \\
\text { error }\end{array}$ & $t$ statistic & $P$ value \\
\hline Intercept & 0.4698 & 0.0826 & 5.6852 & 0.0000 \\
Veg $\times$ tissue & 0.9583 & 0.0715 & 13.4049 & 0.0000 \\
Gluc mean & 0.1157 & 0.0117 & 9.9139 & 0.0000 \\
\hline
\end{tabular}

a Veg = broccoli or cauliflower, tissue = root or shoot, and gluc mean = mean amount of indole glucosinolates. 
significantly higher than in noninoculated plants (Fig. 8B). Lignin concentration was also higher at 28 days after inoculation in cauliflower inoculated at 4 to 6 weeks postemergence compared with the nontreated control (Fig. 8B). However, changes in lignin content did not differ from the nontreated control for cauliflower plants inoculated at 1, 2, or 3 weeks postemergence (Fig. 8B). Across all sample times, lignin concentration was significantly higher in inoculated broccoli plants compared with inoculated cauliflower $(P=0.0001)$.

\section{DISCUSSION}

The spatial and temporal interaction of $V$. dahliae with broccoli or cauliflower was studied directly with the aid of a green fluorescent protein (GFP)-labeled $V$. dahliae isolate and indirectly by reisolating the fungus from sectioned roots and stems and from seed. Whereas previous studies established the differential interaction of $V$. dahliae with Brassica host and nonhost plants $(39,43)$, few examined the changes in phytochemical responses associated with these differential interactions. We report that changes in phenolic and lignin content corresponded to the differential colonization patterns of $V$. dahliae on broccoli and cauliflower. Differences in glucosinolate content were also observed and may contribute to $V$. dahliae resistance in broccoli relative to cauliflower.

Conidia of $V$. dahliae germinated along the root surface or attached to the root hairs with no observable difference between
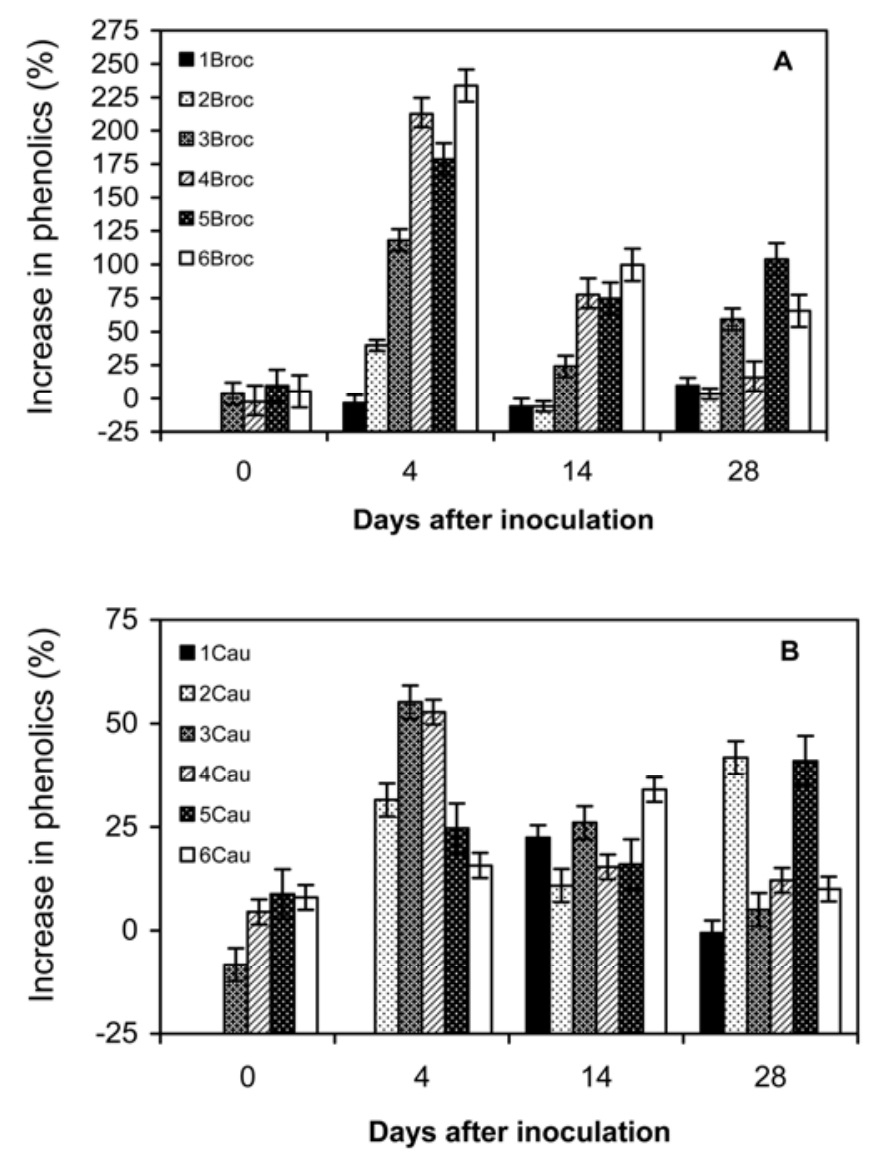

Fig. 7. Percent increase in phenolic content in the roots of $\mathbf{A}$, broccoli (Broc) and $\mathbf{B}$, cauliflower (Cau) plants inoculated with Verticillium dahliae relative to the control. Plants were inoculated at 1, 2, 3, 4, 5, or 6 weeks postemergence. Each value represents three triplicate samples per replication for three replications. For seedlings sampled during 1 to 3 weeks postemergence, one sample consisted of 10 plants whereas, for seedlings sampled at 4 weeks postemergence and beyond, a sample consisted of 5 plants. Error bars represent one standard error of the mean. broccoli and cauliflower, regardless of plant age at the time of inoculation. Similar to prior studies of $V$. dahliae $(4,10,50)$, colonization was initiated at the root tips, through wounds on the root surface, and at the junctions of lateral and main roots. However, unlike prior studies of $V$. dahliae on lettuce (Lactuca sativa) (50) or potato (Solanum tuberosum) (4) or V. albo-atrum on cotton (Gossypium hirsutum) (11), no appressoria were observed during infection, similar to colonization studies of $V$. dahliae on other Brassica hosts $(8,55)$. The wild-type strain used in this study, VdBob70, is typical of other strains that infect Brassica crops and produces microsclerotia similar to $V$. dahliae. However, it is considered a variant of $V$. dahliae because it produces conidia that are significantly longer than those of typical $V$. dahliae strains. Since the initial description by Stark in 1961, the long-spored, Brassica spp.-infecting strains of $V$. dahliae were named $V$. dahliae var. longisporum and subsequently elevated to $V$. longisporum (19); the final taxonomic status remains a highly debated topic (23).

Observed differences in the colonization of cauliflower and broccoli by the GFP-labeled V. dahliae isolate matched previous reports $(39,43)$. Younger cauliflower plants were more susceptible, with $16 \%$ of the seedlings wilting at 1 week after emergence. Even though cauliflower plants inoculated at 2 to 6 weeks postemergence did not wilt, $V$. dahliae colonization of the root and stem xylem was more intense compared with broccoli based on microscopic observations and the frequency of pathogen recovery on a semiselective medium. By 1 month postinoculation,


Fig. 8. Percent increase in lignin content in the roots of $\mathbf{A}$, broccoli (Broc) and B, cauliflower (Cau) plants inoculated with Verticillium dahliae relative to the control. Plants were inoculated at 1, 2, 3, 4, 5, or 6 weeks postemergence. Each value represents three triplicate samples per replication for three replications. For seedlings sampled during 1 to 3 weeks postemergence, one sample consisted of 10 plants whereas, for seedlings sampled at 4 weeks postemergence and beyond, a sample consisted of 5 plants. Error bars represent one standard error of the mean. 
V. dahliae had infected the root xylem of all inoculated cauliflower plants. This is in stark contrast to broccoli, where only sparse colonization of $V$. dahliae was observed in the root xylem of plants inoculated at 1 to 3 weeks after emergence. These differences in the vascular colonization of root tissues were apparent 1 month postinoculation to seed-set. Similarly, xylem tissues in the stems of cauliflower were always infected, whereas again only sparse colonization was observed in the stem of broccoli plants inoculated at 1 to 3 weeks after emergence. Colonization of broccoli plants inoculated at 4 to 6 weeks after emergence was limited to root cortical infections only. Shetty et al. (39) reported that $V$. dahliae in broccoli was limited to cortical tissues and was not observed in xylem tissues of broccoli; these findings were likely a limitation of the immunohistochemical staining assay (does not stain vascular tissues) used in that study. In this study, $V$. dahliae was observed in the xylem tissues of roots and stems of broccoli after inoculation, though sparsely compared with infected cauliflower plants. It is possible that the observed GFP signal was from conidia trapped in the xylem vessels. This might explain why $V$. dahliae was recovered from stems but rarely observed. The fungus moved systemically into the stem via the xylem vessels of both plant species. Even though $V$. dahliae was observed in the xylem of both broccoli and cauliflower, differences in the infection and colonization of vascular tissues within cauliflower and broccoli were quickly apparent after infection.

Although $V$. dahliae was only observed in cauliflower seed, the fungus could not be recovered from seed of inoculated cauliflower or broccoli plants. It is possible that the level of infection was too low to allow efficient recovery from the seed. To our knowledge, the presence of the fungus in cauliflower seed has not been reported previously. Verticillium wilt caused by $V$. dahliae is seedborne in lettuce $(49,50)$, spinach (Spinacia oleracea L.) (6), and in many weed species (49); therefore, it is possible that the disease could also be seedborne in cauliflower.

Our study clarifies the nature of the interaction of broccoli with V. dahliae. All commercial cauliflower cultivars are susceptible to $V$. dahliae and broccoli cultivars are either resistant or immune $(2,39)$. Thus, inclusion of additional cultivars of either crop is unlikely to have altered the conclusions from this study. Bhat and Subbarao (2) inoculated five commercial broccoli cultivars with $V$. dahliae from different hosts and reported that broccoli was resistant to $V$. dahliae isolates from cruciferous hosts and immune to isolates from non-crucifer hosts. We confirmed that broccoli was resistant to $V$. dahliae, in that it did not develop symptoms of vascular wilt and exhibited only limited colonization of vascular tissues relative to cauliflower. Whether the interaction of broccoli- $V$. dahliae should be characterized as a resistant or a nonhost interaction is open to debate $(31,34,46)$. Unlike cauliflower, $V$. dahliae did not extensively colonize broccoli plants inoculated at 4 to 6 weeks postemergence and was rarely observed within the stem xylem tissues of infected plants. Citrus rootstocks are generally referred to as tolerant rather than resistant, because fibrous roots become infected (53). Therefore, because broccoli roots get infected, tolerance or partial resistance could also be used to describe the broccoli- $V$. dahliae interaction.

Nonhost and host-pathogen interactions are influenced by preformed and induced plant defenses $(17,29,31,34,36,45)$. Our results show that phenolics and lignin significantly increased in cauliflower and broccoli 4 to 28 days postinfection compared with noninoculated plants. In addition, the increase was comparatively higher in broccoli relative to that in cauliflower. Therefore, the post-inoculation increase in phenolic compounds and lignin may account for the apparent differential interaction of $V$. dahliae with broccoli and cauliflower.

During infection and colonization, the speed of lignification (17) and phenolic accumulation may be important for successful plant defense. The role of phenolics and lignin in protection against microbial attack is well accepted. However, it is less well understood whether phenolics inhibit fungal growth by being toxic or by strengthening the cell wall. For lignification, the definitive evidence for the importance of structural strengthening of cell wall in penetration resistance is rare $(17,29)$. We report that, in our study, phenolic compounds and lignin accumulated more rapidly and in higher concentrations in broccoli than in cauliflower, corresponding with the apparent resistance of broccoli to $V$. dahliae.

Glucosinolates, too, are associated with plant defense against pathogens $(5,19,35,37,47)$. Certain fungi that have evolved in the presence of glucosinolate-containing plants have probably developed mechanisms similar to specialized Brassicaceae pests to avoid being antagonized by the glucosinolate-myrosinase plant defense system (37). The ability of $V$. dahliae to infect and cause wilt in cauliflower means that it, too, is able to overcome the glucosinolate defense system in cauliflower. $V$ dahliae, however, does not cause wilt in broccoli, which has a different glucosinolate profile than cauliflower. Because the antimicrobial effects of certain glucosinolates and their breakdown products differ based on the R group of the parent glucosinolate $(27,28,41,42)$, it is possible that the different glucosinolates present in broccoli may play a role in defense against $V$. dahliae.

Of the glucosinolates measured, the aliphatic glucosinolate glucoraphanin was detected exclusively in shoots and roots of broccoli and was the only glucosinolate unique to broccoli. Other studies have similarly found that glucoraphanin is either absent or only present at low levels in cauliflower tissues (20,51). Although glucoraphanin was absent from cauliflower tissues, other studies have documented its presence in seed at varying levels depending on the cultivar; however, levels are considerably less than in seed of broccoli cultivars (52). Myrosinase-dependent hydrolysis of glucoraphanin produces sulforaphane and sulforaphane nitrile. In Arabidopsis, glucoraphanin is the predominant glucosinolate (15), of which sulforaphane (4-methylsulphinylbutyl ITC) caused a $50 \%$ growth inhibition of several bacterial and fungal plant pathogens in vitro, including the fungal root and vascular pathogens $F$. culmorum, F. oxysporum f. sp. matthiolae, and V. dahliae (47). An Arabidopsis glucosinolate biosynthesis mutant, gsml-1, deficient in glucoraphanin and its hydrolysis byproducts, was more susceptible to $F$. oxysporum based on disease severity and quantitative reverse-transcription polymerase chain reaction measurement of in planta fungal biomass but not to several other foliar pathogens (47) or the clubroot pathogen Plasmodiophora brassicae (25). Bednarak et al. (1) recently reported a novel myrosinase in Arabidopsis that actively hydrolyzes 4-methoxyglucobrassicin (4-methoxyindol-3-ylmethylglucosinolate) near attempted fungal penetration sites. Together, these prior studies demonstrate that glucosinolate metabolism may play a larger role in active plant defenses against microbial pathogens, even vascular pathogens, than previously realized.

In contrast, the phenological accumulation of glucoiberin, progroitrin, glucosiberin, and neoglucosiberin were noticeably distinct to cauliflower in this study; of which glucoiberin and neoglucobrassicin were detected exclusively in cauliflower. It is quite possible that $V$. dahliae has evolved means to metabolize certain glucosinolates to its advantage.

$V$. dahliae has been shown to have myrosinase activity and can break down glucosinolates. Wu and Meijer (54) exposed Brassica pathogens Phoma lingam, Sclerotinia sclerotiorum, and $V$. dahliae to intact glucosinolates in vitro. Their results showed that, of the three, $V$. dahliae and $P$. lingam could degrade glucosinolates and that the germination and mycelial growth were not affected by the degradation byproducts. In concert with this, Karapapa et al. (19) showed that the noncompatible $V$. dahliae isolate from cotton was more susceptible in vitro to glucosinolate degradation byproducts compared with the compatible $V$. longisporum isolates from sugar beet, oilseed rape, wild radish, and horseradish. However, they did not assay for fungal myrosinase activity. In this study, we did 
not assay VdBob70 or any of the GFP-tagged isolates for myrosinase activity or expose isolates in vitro to glucosinolates found in broccoli and cauliflower. Because certain glucosinolates have greater antagonistic effect against pathogens adapted to glucosinolate-containing plants (12), it is likely that the different glucosinolates present in broccoli are more antagonistic to $V$. dahliae and also that $V$. dahliae is not affected by glucosinolates present in cauliflower. Even among specialist feeders, certain glucosinolates may have a greater antagonistic effect against them (12). The $V$. dahliae-broccoli interaction as influenced by broccoli could further be clarified by inoculating the fungus to broccoli plants that have low glucosinolates content, or perhaps by utilizing segregating populations derived from broccoli $\times$ cauliflower crosses.

In conclusion, the unique ability of broccoli to resist infection by $V$. dahliae has led to successful adaptation of rotations of susceptible crops with broccoli. The factors that possibly contribute to the resistance in broccoli against $V$. dahliae elucidated in this study may lead to an even greater adaptation of rotations with this crop as an alternative disease management practice to soil fumigation.

\section{LITERATURE CITED}

1. Bednarek, P., Pislewska-Bednarek, M., Svatoš, A., Schneider, B., Doubský, J., Mansurova, M., Humphry, M., Consonni, C., Panstruga, R., Sanchez-Vallet, A., Molina, A, and Schulze-Lefert, P. 2009. A glucosinolate metabolism pathway in living plant cells mediates broadspectrum antifungal defense. Science 323:101-106.

2. Bhat, R. G., and Subbarao, K. V. 2001. Reaction of broccoli to isolates of Verticillium dahliae from various hosts. Plant Dis. 85:141-146.

3. Bones, A. M., and Rossiter, J. T. 1996. The myrosinase-glucosinolate system, its organization and biochemistry. Physiol. Plant. 97:194-208.

4. Bowers, J. H., Reidel, R. M., and Rowe, R. C. 1992. Infection of potato root tips by Verticillium dahliae as affected by Pratylenchus penetrans and $P$. crenatus. (Abstr.) Phytopathology 82:1089.

5. Clay, N. K., Adio, A. M., Denoux, C., Jander, G., and Ausubel. F. M. 2009. Glucosinolate metabolites required for an Arabidopsis innate immune response. Science 323:95-101.

6. du Toit, L. J., Derie, M. L., and Hernandez-Perez, P. 2005. Verticillium wilt in spinach seed production. Plant Dis. 89:4-11.

7. EEC Regulation No. 1864/90. Enclosure VIII. Office J. Eur. Commun. L170:27-34.

8. Eynck, C., Koopemann, B., Grunewaldt-Stoecker, G., Karlovsky, P., and von Tiedemann, A. 2007. Differential interactions of Verticillium longisporum and $V$. dahliae with Brassica napus detected with molecular and histological techniques. Eur. J. Plant Pathol. 118:259-2743.

9. Fahey, J. D., Zalcmann, A. T., and Talalay, P. 2001. The chemical diversity and distribution of glucosinolates and isothiocyantes among plants. Phytochemistry 56:5-51.

10. Fradin, E. F., and Thomma, B. P. H. J. 2006. Physiology and molecular aspects of Verticillium wilt diseases caused by $V$. dahliae and V. alboatrum. Mol. Plant Pathol. 7:71-86.

11. Garber, R. H., and Houston, B. R. 1966. Penetration and development of Verticillium albo-atrum in the cotton plant. Phytopathology 56:11211126.

12. Giamoustaris, A., and Mithen, R. 1995. The effects of modifying the glucosinolate content of leaves of oilseed rape (Brassica napus ssp. oleifera) on its interaction with specialist and generalist pests. Ann. Appl. Biol. 126:347-363.

13. Goodwin, T. W., and Mercer, E. I. 1983. Introduction to Plant Biochemistry, 2nd ed. Butterworth Heinemann, UK.

14. Hartfield, R. D., and Weimer, J. P. 1995. Degradation characteristics of isolated and in-situ cell-wall Lucerne pectic polysaccharides by mixed ruminal microbes. J. Sci. Food Agric. 69:185-196.

15. Haughn, G. W., Davin, L., Giblin, M., and Underhill, E. W. 1988. Biochemical genetics of plant secondary metabolites in Arabidopsis thaliana. Plant Physiol. 97:217-226.

16. Hoglund, A. S., Lenman, M., Falk, A., and Lars Rask, L. 1991. Distribution of myrosinase in rapeseed tissues. Plant Physiol. 95:213-231.

17. Hückelhoven, R. 2007. Cell wall-associated mechanisms of disease resistance and susceptibility. Annu. Rev. Phytopathol. 45:101-127.

18. Kabir, Z., Bhat, R. G., and Subbarao, K. V. 2004. Comparison of media for recovery of Verticillium dahliae from soil. Plant Dis. 88:49-55.

19. Karapapa, V. K., Biag, M. A., Heale, J. B., and Rossiter, J. T. 1997. Glucosinolate response in winter oilseed rape Brassica napus ssp. oleifera to Verticillium dahliae (non-pathogenic) and V. longisporum comb. nov., (Karapapa, Bainbridge and Heale, 1997) (pathogenic). Pages 196-203 in: Advances in Verticillium Research and Disease Management. E. C. Tjamos., R. C. Rowe., J. B. Heale., and D. R. Fravel, eds. American Phytopathological Society, St. Paul, MN.

20. Khang, C., Park, S.-Y., Rho, H., Lee, Y., and Kang, S. 2006. Agrobacterium tumefaciens-mediated transformation and mutagenesis of filamentous fungi Magnaporthe grisea and Fusarium oxysporum. Pages 403-420 in: Agrobacterium Protocols. K. Wang, ed. Humana Press, Totowa, NJ.

21. Kim, D. O., Padilla-Zakour, O. I., and Griffiths, P. D. 2004. Flavonoids and antioxidant capacity of various cabbage genotypes at juvenile stage. J. Food Sci. 69:685-689.

22. Kirkegaard, J. A., and Sarwar, M. 1998. Biofumigation potential of brassicas. I. Variation in plant glucosinolate profiles of diverse field grown brassicas. Plant Soil 201:71-89.

23. Klosterman, S. J., Attalah, Z. K., Vallad, G. E., and Subbarao, K. V. 2009. Diversity, pathogenicity, and management of Verticillium species. Annu. Rev. Phytopathol. 49:39-62.

24. Koike, S. T., Subbarao, K. V., Davis, R. M., Gordon, T. R., and Hubbard, J. C. 1994. Verticillium wilt of cauliflower in California. Plant Dis. 78:1116-1121.

25. Ludwig-Müller, J., Pieper, K., Ruppel, M., Cohen J. D., Epstein, E., Kiddle, G., and Bennett, R. 1999. Indole glucosinolate and auxin biosynthesis in Arabidopsis thaliana (L.) Heynh. glucosinolate mutants and the development of clubroot disease. Planta 208:409-419.

26. Magrath, R., Herron, C., Giamoustaris, A., and Mithen, R. 1993. The inheritance of aliphatic glucosinolates in Brassica napus. Plant Breed. 111:55-72.

27. Manici, L. M., Lazzeri, L., and Palmieri, S. 1997. In vitro fungitoxic activity of some glucosinolates and their enzyme-derived products towards pathogenic fungi. J. Agric. Food Chem. 45:2768-2773.

28. Mayton, H. S., Olivier, C., Vaughn, S. F., and Loria, R. 1996. Correlation of fungicidal activity of Brassica species with allyl isothiocyanate production in macerated leaf tissue. Phytopathology 86:267-271.

29. Mclusky, S, R., Bennett, M. H., Beale, M. H., Lewis, M. J., Gaskin, P., and Mansfield, J. W. 1999. Cell wall alterations and localized accumulation of feruloyl-3'-methoxytyramine in onion epidermis at sites of attempted penetration by Botrytis allii are associated with actin polarization, peroxidase activity and suppression of flavonoid biosynthesis. Plant J. 17:523-534.

30. Mithen, R. 2001. Glucosinolates-biochemistry, genetics and biological activity. Plant Growth Regul. 34:91-103.

31. Mysore, K. S., and Ryu, C.M. 2004. Nonhost resistance: how much do we know? Trends Plant Sci. 9:97-103.

32. Njoroge, S. M. C., Park, S., Kang, S., Koike, S. T., and Subbarao, K. V. 2008. Comparative analysis of infection of broccoli and cauliflower by a green fluorescent protein-tagged Verticillium dahliae isolate. (Abstr.) Phytopathology 98:S114.

33. Njoroge, S. M. C., Riley, M. B., and Keinath, A. P. 2008. Effect of incorporation of Brassica spp. residues on population densities of soilborne microorganisms and on damping-off and Fusarium wilt of watermelon. Plant Dis. 92:287-294.

34. Nürnberger, T., and Lipka, V. 2005. Non-host resistance in plants: New insights into an old phenomenon. Mol. Plant Pathol. 6:335-345.

35. Pawel, B., Pislewska-Bednarek, M., Svatoš, A., Schneider, B., Doubský, J., Mansurova, M., Humphrey, M., Consonni, C., Panstruga, R., SanchezVallet, A., Molina, A., and Schulze-Lefert, P. 2009. A glucosinolate metabolism pathway in living plant cells mediates broad-spectrum antifungal defense. Science 323:101-106.

36. Pomar, F., Novo, M., Bernal, M. A., Merino, F., and Barcelo, A. R. 2004. Changes in stem lignins (monomer composition and crosslinking) and peroxidase are related with the maintenance of leaf photosynthetic integrity during Verticillium wilt in Capsicum annиum. New Phytol. 163:111-123.

37. Rask, L., Andréasson, E., Ekbom, B., Eriksson, S., Pontoppidan, B., and Meijer, J. 2000. Myrosinase: Gene family evolution and herbivore defense in Brassicaceae. Plant Mol. Biol. 42:93-113.

38. Sarwar, M., Kirkegaard, J. A., Wong, P. T. W., and Desmarchelier, J. M. 1998. Biofumigation potential of brassicas. III. In vitro toxicity of isothiocyanates to soil-borne fungal pathogens. Plant Soil 201:103-112.

39. Shetty, K. G., Subbarao, K. V., Huisman, O. C., and Hubbard, J. C. 2000. Mechanism of broccoli-mediated Verticillium wilt reduction in cauliflower. Phytopathology 90:305-310.

40. Singleton, V. L., and Rossi, J. A. 1965. Colorimetry of total phenolics with phosphomolybdic-phosphotungstic acid reagents. Am. J. Enol. Vitic. 16:144-158.

41. Smolinska, U., and Horbowicz, M. 1999. Fungicidal activity of volatiles from selected cruciferous plants against resting propagules of soil-borne fungal pathogens. J. Phytopathol. 147:119-124. 
42. Smolinska, U., Morra, M. J., Knudsen, G. R., and James, R. L. 2003. Isothiocyantes produced by Brassicaceae species as inhibitors of Fusarium oxysporum. Plant Dis. 87:407-412.

43. Subbarao, K. V., Chassot, A., Gordon, T. R., Hubbard, J. C., Bonello, P., Mullin, R., Okamoto, D., Davis, R. M., and Koike, S. T. 1995. Host range of Verticillium dahliae from cauliflower and genetic relationships and cross pathogenicities of isolates from different crops. Phytopathology 86:1105-1112.

44. Subbarao, K. V., Hubbard, J. C., and Koike, S. T. 1999. Evaluation of broccoli residue incorporation into field soil for Verticillium wilt control in cauliflower. Plant Dis. 83:124-129.

45. Taiz, L., and Zieger, E. 1998. Plant Physiology. Sinauer Associates Inc., Sunderland, MA.

46. Thordal-Christensen, H. 2003. Fresh insights into processes of nonhost resistance. Curr. Opin. Plant Biol. 6:351-357.

47. Tierens, K. F. M. J., Thomma, B. P. H. J., Brouwer, M., Schmidt, J., Kistner, K., Prozel, A., X. Mauch-Mani, B., Cammue, B. P. A., and Broekaert, W. F. 2001. Study of the role of antimicrobial glucosinolatederived isothiocyantes in resistance of Arabidopsis to microbial pathogens. Plant Physiol. 125:1688-1699.

48. Torti, S. D., Dearing, M. D., and Kursar, T. A. 1995. Extraction of phenolic compounds from fresh leaves: A comparison of methods. J. Chem. Ecol. 21:117-125.
49. Vallad, G. E., Bhat, R. G., Koike, S. T., Ryder, E. J., and Subbarao, K. V. 2005. Weedborne reservoirs and seed transmission of Verticillium dahliae in lettuce. Plant Dis. 89:317-324.

50. Vallad, G. E., and Subbarao, K. V. 2008. Colonization of resistant and susceptible lettuce cultivars by a green fluorescent protein-tagged isolate of Verticillium dahliae. Phytopathology 98:871-885.

51. Verkerk, R., Tebbenhoff, S., and Dekker, M. 2010. Variation and distribution of glucosinolates in 42 cultivars of Brassica oleracea vegetable crops. Acta Hortic. 856:63-70.

52. West, L. G., Meyer, K. A., Balch, B. A., Rossi, F. J., Schultz, M. R., and Haas, G. W. 2004. Glucoraphanin and 4-hydroxyglucobrassicin contents in seeds of 59 cultivars of broccoli, raab, kohlrabi, radish, cauliflower, Brussels sprouts, kale, and cabbage. J. Agric. Food Chem. 52:916-926.

53. Widmer, T. L., Graham, J. H., and Mitchell, D. J. 1998. Histological comparison of fibrous root infection of disease-tolerant and susceptible citrus hosts by Phytophthora nicotianae and $P$. palmivora. Phytopathology 88:389-395.

54. Wu, X. M., and Meijer, J. 1999. In vitro degradation of intact glucosinolates by phytopathogenic fungi of Brassica. In: Proc. 10th Int. Rapeseed Congr. Canberra, Australia.

55. Zhou, L., Hu, Q., Johansson, A., and Dixelius, C. 2006. Verticillium longisporum and $V$. dahliae: Infection and disease in Brassica napus. Plant Pathol. 55:137-144. 